\title{
Organisational and Economic Mechanism of Implementation of the Model of «Innovative Elevator»
}

\author{
Ekaterina Alexandrovna Ugnich ${ }^{1}$ \\ ${ }^{1}$ Don State Technical University, Gagarin Square, Rostov-on-Don, Russian Federation \\ Correspondence: Ekaterina Alexandrovna Ugnich, Don State Technical University, 344001, Gagarin Square, \\ Rostov-on-Don, Russian Federation. E-mail: ugnich77@mail.ru
}

\author{
Received: July 10, 2014 Accepted: July 21, 2014 Online Published: November 27, 2014 \\ doi:10.5539/ass.v10n24p57 URL: http://dx.doi.org/10.5539/ass.v10n24p57
}

\begin{abstract}
The process of acceleration of scientific and technical progress requires such mechanisms and institutions which will be aimed at the formation of synergistic effect within the frameworks of building of innovative economy. The article deals with the problems and prospects of the realization of venture financing mechanism. The raise in efficiency of venture capital financing is a topical issue not only within the frameworks of the emerging innovative economy in Russia, but also for the developed countries, which have long moved on the rails of innovative development. This research work is devoted to the quest of the most optimal model of the mechanism of venture funding. The combination of various development institutions, which allow the project to move by the type of an "innovative elevator", the unified approach to the management of the project at all its stages on the basis of special principles form the further prospects of venture business. The aim of this research work is to develop a model of venture capital financing, aimed at stage-by-stage (stepwise) implementation of innovative projects through the mechanism of "innovative elevator".
\end{abstract}

Keywords: venture capital financing, "innovative elevator", development institutions

\section{Introduction}

New paradigm of modern state's economic development marked as a keynote the necessity of intensification of innovative process. The formation of innovative economy is the main systemic process that largely determines the role and place of the country in world economy, its international competitiveness, economic independence and security.

Modern researches are characterized by a great number of approaches to the analysis of mechanisms and instruments of the management of economy's innovative development However, the main problem still remains the problem of successful implementation of innovative process, which consists in uninterrupted provision of all its stages, starting with fundamental researches and ending in the sphere of products' usage. Economic practice developed a special mechanism which contributes to the transfer of the results of researches and development into a commercial product. It became venture capital financing. The term "venture" it emphasizes the risky nature of investments connected mostly with innovative activity. The emergence of new industries such as semiconductors, biotechnology, and the internet, as well as the introduction of several innovations across a spectrum of sectors in health-care, information technology, and new materials, has been driven in large part by the availability of venture capital for new startups (Nanda \& Rhodes-Kropf, 2013). Financing radical innovations, however, requires more than just capital. It requires a mindset of experimentation and a willingness to fail. The modal outcome of a venture capital investment is complete failure. Hall \& Woodward (2010) report that about $50 \%$ of the venture capital-backed startups in their sample had zero-value exits. Sahlman (2010) finds that $85 \%$ of returns come from just $10 \%$ of investments. Theory of venture capital financing has found its reflection in work of Hellmann (1998), Kortum \& Lerner (2000), Landström (2007), Peneder (2010), Puri \& Zarutskie (2007), Zhang (2007).

Development of venture capital financing is one of the most topical issues of innovative economy's formation in Russia. Despite the fact that in recent years venture capital business has been developing rapidly enough, the necessary infrastructure of support has been created, legislative base is constantly improving, the volume of venture capital investments is increasing, there are stories of success of venture projects, definite problems still exist. The institutional conditions established have a great impact on the existing mechanism of venture capital 
financing, which cannot function as a single coherent mechanism contributing to the development of the innovative process. The existing supporting institutions of venture business are not always interconnected and effective.

\section{Methods}

In modern context the development of venture capital financing in Russia is one of the most topical problems of innovative economy formation. Despite the fact that in recent year's venture capital business has been flourishing, the necessary supportive infrastructure has been created, the legislative base is constantly improving, the volume of venture capital investments is increasing, there are a number of stories of success of venture projects, and still there are some problems. The prevailing institutional conditions have a great impact on the existing mechanism of venture capital financing, which cannot function as a single coherent mechanism contributing to the development of the innovation process. The existing supportive institutions of venture business are not always interconnected and effective. Experts explain that the situation is due to lack of a system of efficiency appraisal and control of business incubators and industrial parks activities by the state.

The aim of this research work is to develop a model of venture capital financing, aimed at stage-by-stage (stepwise) implementation of innovative projects through the mechanism of "innovative elevator". The research work is based on the principles of structural and functional approaches, as well as the methods of analysis and synthesis on theoretical and empirical levels. The methods mentioned are used within the frameworks of a systematic approach that contributes to the argumentation of the results made by the author.

\section{Results}

\subsection{The Peculiarities of Venture Capital Financing in Russian Economy}

At the present stage one of the peculiarities of functioning of Russian economic system is the prolonged transitional period of "finding ways" able to provide a qualitatively new stage of society's development on the basis of factors of innovative growth. At the same time the formation of "new economy" should be based not just simply on the adaptation to modern world trends, but on the search and implementation of Russia's strategic advantages in modern world.

At the same time Russian economy demonstrates pretty low rates of innovative development. Thus, in the period from 2009-2011 the share of high-tech sector in GDP constituted only $0.9 \%$. For comparison in developed countries the share of high-tech science-consuming enterprises in GDP exceeds $2 \%$, in Korea-more than 5\%. Technological innovations are carried out by not more than $10 \%$ of Russian enterprises; the share of innovative products in ready-made form occupies less than 5\% (Eremin et al., 2011).

Low level of innovative development in Russia is largely conditioned by a number of problems in the sphere of continuous provision of alternation of stages of innovative process. The first several years of existence of an innovative project, when risks are at their maximum, analysts call the "valley of death". It is the stage when the attraction of financial resources is accomplished with much difficulty, what is frequently aggravated by negative monetary flows within the frameworks of the project itself. The specifics of the innovative process, the necessity to overcome the "valley of death" form a specific particular mechanism which involves into the innovative process quite large volumes of capital and optimizes the structure of the risks. This mechanism, which first appeared in the middle of the twentieth century in the USA, is considered to be venture capital financing.

The emergence of venture capital financing in Russia as a source of financing of innovations is conditioned by the change in socio-economic system. Radical economic reform which began in 1992 freed the way to the development of business initiative. Further development of domestic venture capital financing is connected with the changes in market conjuncture, the establishment of legal and regulatory conditions for its functioning.

In recent years Russian venture capital business has been developing rather turbulently. In research of Dow Jones Venture Source is noted the rise in venture capital inflow to Russia since 2009, and its volume in 2012 is estimated at 237 million euros. In terms of the volume of investments in high-tech brunches Russia occupies the 4th place in Europe. More often there appears and real stories of success of Russian venture projects. At the same time Russian practice registers weak connection of venture capital financing and "breakthrough" industries, ensuring steady economic development based on the extension of innovations. Thus, according to "Expert" magazine in comparative expression the annual venture capital investments in Russia still do not exceed $0.01 \%$ of GDP. Just to compare, the volume of venture capital investments in the U.S.A. is not less than $0.2 \%$ of GDP of the country. Thus, even judging by the volume of the investments, venture capital financing in Russia is not able to stimulate actively innovative development of the economy. 


\section{2 "Innovative Elevator" as a Mechanism of Support of the Innovative Process}

In spite of all the supporting measures being taken the results of innovative development of national economy differ significantly from the expected ones. Numerous studies are dedicated to the search of the answers to the challenges facing emerging economy of the new type. In particular, the model of "innovative elevator" is quite popular. The notion of "innovative elevator" appeared in economic "everyday elevator" in April, 2010 with the signing of the "Agreement of Ten" which regulates the interaction of the established in Russia development institutions. The system of "innovative elevator" includes the institutions which allow enterprises, predominantly small and medium ones, implementation of the projects from the scientific research stage up to the formation of competitive enterprises and innovative products. The basis of the concept of "innovative elevator " constitutes the idea of acceleration of the innovative process, the creation and promotion of new technologies, the rapid formation of the institutions-mechanisms of increase in mobility of R \& D (Research \& Development)-active, innovative enterprises (Гурунян, 2013).

"Innovative elevator" promotes the project through the stages of innovative process by means of special supporting institutions. Each stage of the promotion of an innovative project requires special instruments of support. At seeding stage one needs infrastructural support, which allows converting the idea into an innovative project. At start-up stage and "early growth stage" one needs support in creation of a prototype and a business plan, launching the first line of the production and emergence of an innovative product on the wide market. At the stage of expansion it is necessary to ensure accelerated expansion of the market share and increase in volumes of the production in accordance with strategic plans.

Each stage of innovative project implementation requires development of specific strategy aimed at reduction of the risk and search of the appropriate sources of funding. In particular, at early stages of the development of an innovation-in the period of the transition through "the valley of death"-active investment strategy and support are required, which imply not only specific sources of funding, but also investment of experience into future innovative product, knowledge in the sphere of management and business modeling. For the later stages of innovations' realization passive investment strategies are suitable which provide an opportunity for innovative company-developers to capitalize. The success of innovative activity, besides the correct strategy chosen, depends largely on the effectiveness of supporting institutions. In today's domestic and foreign practice there are various institutions of infrastructure aimed at the support of innovative activity. The existing in Russian practice development institutions (Vnesheconombank, JSC "RUSNANO“ Russian Venture Company (RVC), JSC "SME Bank", the Fund of Assistance to small forms of enterprises in science and technology field, "Skolkovo" Fund, Russian Fund for Technological Development) representing the elements of the "innovative elevator", are created to support innovative projects at all stages with the help of various instruments including the promotion to creation of venture capital funds, participation in transfer of the technologies. The main objective of development institutions consists in support of the projects important for the state, technologically complicated and perspective and promising in terms of economic development of the country, financing of which is hindered due to high risks at the expense of private funds.

Infrastructure of support consists of the subjects of venture capital business which contribute to implementation of innovative activity, provide favorable conditions for the provision of services for creation and implementation of venture projects. Activity of the subjects of the "innovative elevator" is not reduced to financial provision represented by institutions carrying out financing of venture projects at different stages of their life cycle-from seeding up to expansion. Versatility of venture business, filled with intellectual contents, its risky nature besides financial provision offers other directions of support necessary to promotion of venture projects. In particular, venture capital business needs personnel provision, legal, organizational and industrial and consulting (advisory) support, information provision, support of the scientific community. However, the existing development institutions are often not coordinated with each other; they do not have a unified approach towards determination of both viability and quality of an innovative project. Nowadays unified standards of assessment of innovative projects which would let not only implement the innovative process, but also increase the activity of the investors are not developed. Serious problem in functioning of the "innovative elevator" is considered to be a "jam" of the project at seeding stage. It is linked with the problem of transformation of the idea into the project and inefficiency of seeding investment.

In its turn absence of unified standards of assessment of innovative projects hampers and sometimes even blocks their access to financial resources. At the same time many domestic and foreign researches have established dependence between increase in innovative activity and availability of venture capital financing. In other words, venture capital financing is extremely important for technology commercialization in those territories in which it is most accessible. Venture capital financing supports the development of entrepreneurial ideas; helps educate 
and encourage business communities able to realize innovative ideas. As far as high-tech enterprises need at the same time both an inventor and an entrepreneur, the mechanism of venture capital financing allows one to implement many of the ideas that have emerged in a particular territory (Samila \& Sorenson, 2010).

The firms, backed by venture capital, grow considerably quicker than other firms (Peneder, 2010). At the same time, venture capital financing mechanism is highly selective. In particular, advantage in financing will have enterprises that have potential of recoupment within the period of 5-7 years through IPO or sale to a strategic investor. That is why venture capital is predominantly investments in managerial capacity of the command, enterprises with competitive advantage which possess already significant sales in combination with great amount of potential consumers (Bhide, 2007).

\section{Discussion}

\subsection{Perspective Mechanism of Venture Capital Financing}

Coming from the stated above, the most perspective will be such an organizational mechanism of venture capital financing which functions under the control of a single center and provides the needs of both investors and innovators. Taking into consideration domestic and foreign experience, we can formulate general principles of a single integrated mechanism aimed at the formation and realization of innovative projects in the form of a model of venture capital financing (Ugnich, 2013). It is based on interconnection of the elements of the "innovative elevator" and differentiated approach to investment strategies and funding sources in dependence on the stage of passing of the project. The offered model of venture capital financing is based on a special "zero waste (waste-free)" mechanism of getting revenue, aimed at minimization of investment risk of innovative projects based on sales of innovative projects on the early stages or output of ready-made business. In its essence this model is a "venture factory" in the basis of which lies a hybrid of a fund, a business-accelerator and a managing company. The model is based on the networking interaction of specialized infrastructural institutions (Figure 1):

1) a business-accelerator, which generates the flow of innovative projects and organizes their packaging. An accelerator is a type of business incubation program that allows entrepreneurial teams and their ventures to connect with and access resourced from investor and other important stakeholders (Malek et al., 2014). Accelerators assist with building the venture team, fine-tuning the idea, and mentoring the business from idea, prototype, through product development (Hoffman \& Radojevich-Kelley, 2012). Accelerators provide intensive, boot-camp training comparable to entrepreneurship classes at the collegiate level (Fishback et al., 2007);

2) a venture capital fund, which finances the projects of mainly later stages (early growth stage, expansion);

3) a crowd investing («crowd investing»-«national investment») platform, which accumulates the funds for the projects of early stages (seeding and start-up). Crowd investing is an investment in a project, accomplished by a great number of micro investors (Mollick, 2013). This mechanism supposes a financial reward for micro investors in an exchange for their support (Maeschle, 2012);

4) a managing company being a single control organ of management by all institutes of infrastructure.

The unity of standards assessment of an innovative project at each stage is provided by means of the control of a unified Managing company, which accompanies all stages of an innovative process, starting with the analysis of the dynamics of possible development of innovative ideas up to the functioning of ready-made business-units.

Functioning of the Managing Company is directed to on an increase in profits for the founders through its participation at every stage of formation and implementation of innovative projects. The Managing Company carries out the management of innovative projects at all stages of their life cycle, including participation in the activities of the specialized infrastructural institutions (business-accelerator, venture capital fund, crowdinvesting platform). To reduce innovative risk the Managing Company must form elaborate plan of actions in regard to every project and in accordance with it select the necessary financial resources and team.

A managing company works on principles of self-repayment, therefore operating charges even on the initial stages will be covered by revenues from the sales of results of analysis of dynamics of innovative development trends. The revenues of the Managing Company are formed at the expense of the following sources:

1) revenues from the sales at all stages of development and implementation of the projects, including the fact that even on the initial stages operating charges will be covered by revenues from the sales of results of analysis of dynamics of innovative development trends;

2) fee from the investors of the corporate venture capital fund;

3) fee from the investors of the corporate crowd investing platform. 


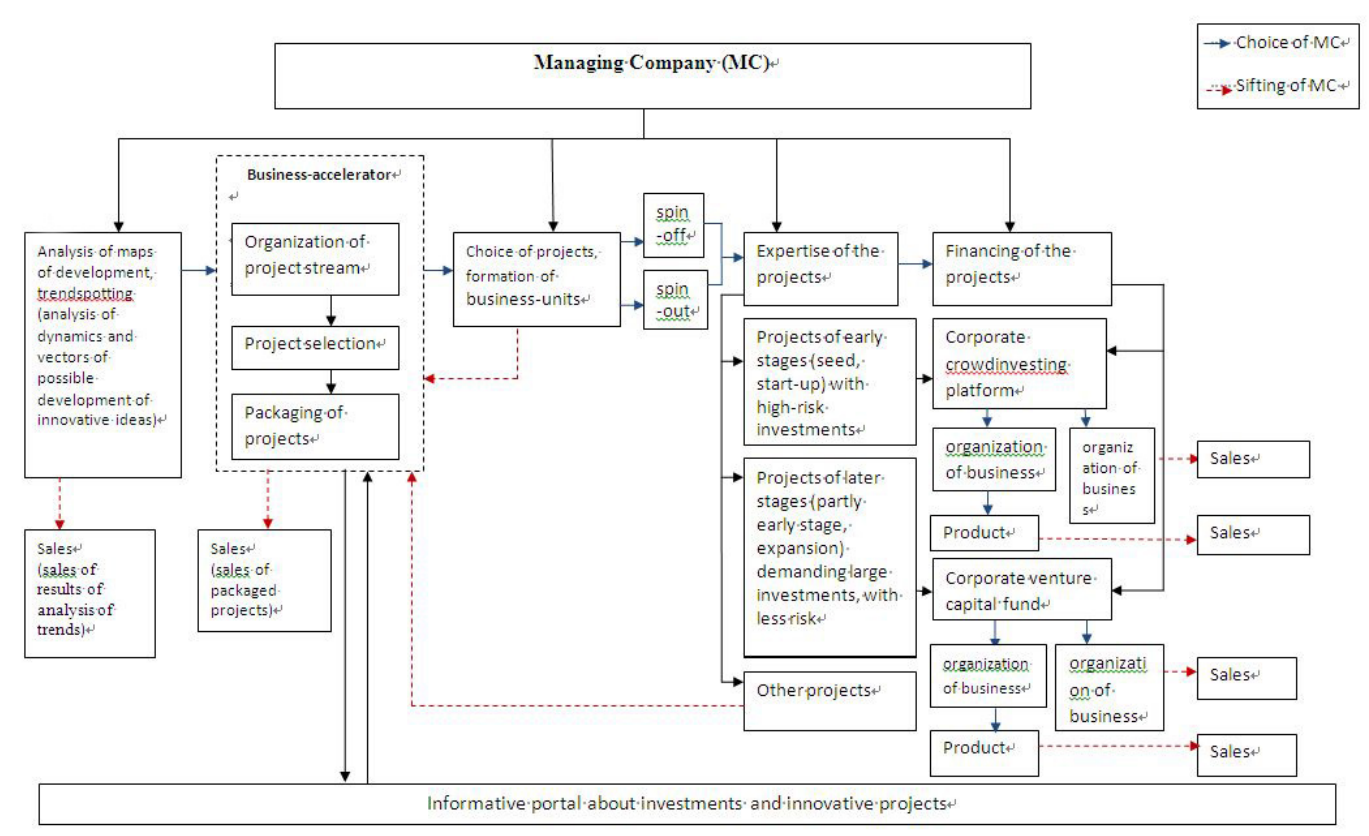

Figure 1. Model of venture financing

The activities of the whole mechanism of "venture factory" should be based on the following principles:

1) fabless-principle allowing to use the division of labor and integrate and effectively use the necessary resources (intellectual, material, financial, etc.) in order to form and implement the projects (Hurtarte et al., 2007). This principle is based on the attraction of the most suitable resources with minimum expenses;

2) generation of search of innovative ideas with their subsequent elaboration;

3) $\mathrm{SbA}$ (support-by-action)-support by action aimed at the result-full immersion of the Managing Company into all stages of the implementation of innovative projects;

4) avoiding losses on every stage of project realization, the provision of the continuity of the flow of incomes;

5) transmission-gradual transition of innovative projects from one stage of implementation to another in case of expediency;

6) network principle based on the coordination of interconnected infrastructural institutions;

7) use of business-transfer of successful foreign technologies.

The mechanism of the presented model of venture capital financing implies also the principles of self-repayment, effectiveness, transparency and flexibility thus contributing to raise in confidence of the investors.

Profit-making is achieved by the investors mainly through the sales of the start-ups, the sales of the results of the analysis of trends and sales of ready-made business in the later stages.

\section{Conclusion}

The presented mechanism of the venture capital financing has certain advantages in the system of financing of innovative projects from which all its participants win. Firstly, this mechanism is based on plenitude and interconnection of all the components of the "innovative elevator" built on network principle. Secondly, unified standards of assessment of projects are used for all institutes of the system. Thirdly, the system of "innovative elevator" on the basis of fabless-principle assists integration and effective use of the necessary for implementation of the project resources. Fourthly, the presented mechanism comprises the stage called pre-seeding, thereby generating the stream of innovations.

The innovators get the formation of an innovative idea into a ready-made complete project; they also have an opportunity to get the necessary funding at the very beginning of the growth of the business, during the transition from the "packaged idea" to its implementation. Apart from this the problem of managing an innovative project at all stages is solved. Due to experience of the managing professionals the probability of bringing the project to its successful implementation increases. For the investors the argument of great importance in favor of investing 
serves increase in profitability under risk reduction. The mechanism of this model allows to increase the investors' profits at the expense of virtually "waste-free" implementation of innovative projects at various stages, including start-ups, and also to reduce investment risk. In addition, the investors get an opportunity of expanding the informational space about availability of innovative projects. On the whole, for the economy there appears a possibility of time ous implementation of new technologies, development of business initiative and animated development of innovative ideas.

\section{References}

Bhide, A. (2007). The Venturesome Economy. Princeton University Press, Princeton.

Eremin, S., Welf, A., \& Boyarski, A. (2011). Industry parks of incubation period. Retrieved October 18, 2013, from http://www.rokf.ru/investment/2011/10/07/094609.html

Fishback, B., Gulbranson, C. A., Litan, R. E., Mitchell, L., \& Porzig, M. (2007). Finding business idols: A new model to accelerate start-ups. Ewing Marion Kauffman Foundation, 2-8.

Gurunyan, T. V. (2013). Investment-innovation lift for small and medium-sized entrepreneurship: Questions of financing Start-Ups. Tomsk State University Journal of Economics, 3(23), 121.

Hall, R. E., \& Woodward, S. E. (2010). The burden of the non-diversifiable risk of entrepreneurship. American Economic Review, 100, 1163-1194. http://dx.doi.org/10.1257/aer.100.3.1163

Hellmann, T. (1998). The Allocation of Control Rights in Venture Capital Contracts. Rand Journal of Economics, 29, 57-76. http://dx.doi.org/10.2307/2555816

Hoffman, D., \& Radojevich-Kelley, N. (2012). Analysis of Accelerator Companies: An Exploratory Case Study of Their Programs, Processes, and Early Results. Small Business Institute Journal, 8(2), 54-70.

Hurtarte, J. S., Wolsheimer, E. A., \& Tafoya, L. M. (2007). Understanding fabless IC technology (p. 273). Newnes.

Kortum, S., \& Lerner, J. (2000). Assessing the contribution of venture capital to innovation. Rand J Econ, 31(4), 674-692. http://dx.doi.org/10.2307/2696354

Landström, H. (2007). Handbook of research on venture capital. Edward Elgar Publishing, Northampton. http://dx.doi.org/10.4337/9781847208781

Maeschle, O. (2012). Which information should entrepreneurs on German crowd investing-platforms disclose? Working Paper \#127, July. Retrieved September 14, 2013, from http://www.wiwi.uni-rostock.de/fileadmin/ Institute/ wp127thuenen.pdf

Malek, K., Maine, E., \& McCarthy, I. P. (2014). A typology of clean technology commercialization accelerators. Journal of Engineering and Technology Management, 32, 26-39. http://dx.doi.org/10.1016/j.jengtecman. 2013.10.006

Mollick, E. (2013). The dynamics of crowd funding: An exploratory study. Journal of Business Venturing, 29(1), 1-14. http://dx.doi.org/10.1016/j.jbusvent.2013.06.005

Nanda, R., \& Rhodes-Kropf, M. (2013). Investment cycle and startup innovation. Journal of Financial Economics, 110, 403-418. http://dx.doi.org/10.1016/j.jfineco.2013.07.001

Peneder, M. (2010). The impact of venture capital on innovation behaviour and firm growth. Venture Capital: An International Journal of Entrepreneurial Finance, 12(2), 83-1071. http://dx.doi.org/10.1080/136910 61003643250

Puri, M., \& Zarutskie, R. (2007). On the Lifecycle Dynamics of Venture-Capital and Non-Venture-Capital-Financed Firms. Journal of Finance, 6, 1-27.

Sahlman, W. (2010). Risk and reward in venture capital. Harvard Business School Note, 811(36), 1-37.

Samila, S., \& Sorenson, O. (2010). Venture capital as a catalyst to commercialization. Opening Up Innovation: Strategy, Organization and Technology (pp. 16-18). At Imperial College London Business School.

Ugnich, E. (2013). The Perfection of the Mechanism of Venture Capital Financing: Organizational and Economic Model. World Applied Sciences Journal, 26(12), 1584-1587.

Zhang, J. (2007). Access to venture capital and the performance of venture capital-backed startup sin Silicon Valley. Economic Development Quarterly, 21, 124-147. http://dx.doi.org/10.1177/0891242406298724

\section{Copyrights}

Copyright for this article is retained by the author(s), with first publication rights granted to the journal.

This is an open-access article distributed under the terms and conditions of the Creative Commons Attribution license (http://creativecommons.org/licenses/by/3.0/). 